\title{
Estudios Gerenciales
}

Journal of Management and Economics for Iberoamerica

Artigo de pesquisa

\section{O impulso da pertença: a influência da identidade social na compra por impulso de jovens Portugueses}

Rita Gonçalves*

Assistente de Investigação, Faculdade de Psicologia e de Ciências a Educação, Universidade do Porto, Porto, Portugal.

rita.bgoncalves@live.com.pt

Samuel Lincoln Bezerra Lins

Professor Auxiliar e Investigador, Faculdade de Psicologia e de Ciências da Educação, Universidade do Porto, Porto, Portugal. samuellins@fpce.up.pt

Sibele Dias de Aquino

Doutoranda, Programa de Pós-Graduação em Psicologia, Pontifícia Universidade Católica do Rio de Janeiro, Rio de Janeiro, Brasil. sibele.aquino@gmail.com

Luana Elayne Cunha de Souza

Professora Adjunta, Programa de Pós-graduação em Psicologia, Universidade de Fortaleza, Fortaleza, Brasil.

luana_elayne@hotmail.com

\section{Resumo}

A compra por impulso é um tema complexo e com variadas influências. Este estudo experimental tem por objetivo analisar o efeito da identidade social, das emoções e da marca do produto na tendência de jovens para comprar sapatilhas por impulso. Participaram 545 jovens portugueses, que responderam a um questionário online sobre um cenário experimental de compra de sapatilhas da marca Adidas. Os resultados indicam que o desconto influencia a compra impulsiva e as emoções positivas medeiam a relação entre identificação com jovens e compra por impulso. Também verificou-se uma propensão à apropriação da marca como um marcador identitário da juventude portuguesa. Assim, além das características do produto, os processos grupais poderão estar relacionados com este comportamento de compra.

Palavras chave: tendência a comprar por impulso; emoções; desconto; juventude; marca; identidade social.

El impulso de la pertenencia: la influencia de la identidad social de los jóvenes Portugueses en la compra por impulso

\section{Resumen}

La compra por impulso es un tema complejo con influencias diversas. Este estudio experimental tuvo como objetivo analizar el efecto de la identidad social, las emociones y la marca del producto en la tendencia de los jóvenes a comprar zapatillas por impulso. Participaron 545 jóvenes portugueses, quienes respondieron un cuestionario en línea sobre un escenario experimental para la compra de zapatillas Adidas. Los resultados indican que el descuento influye en la compra impulsiva y las emociones positivas median la relación entre la identificación con los jóvenes y la compra impulsiva. También hubo una propensión a apropiarse de la marca como marcador de identidad. Así, además de las características del producto, los procesos de grupo pueden estar relacionados con este comportamiento de compra.

Palabras clave: tendencia a la compra por impulso; emociones; descuento; juventud; marca; identidad social.

The impulse of belonging: The influence of social identity of Portuguese youths on impulse buying

\section{Abstract}

Impulse buying is a complex topic with varying influences. This experimental study aimed to analyze the effect of social identity, emotions, and product brand on the tendency of young people to buy sneakers by impulse. 545 young Portuguese took part, who answered an online questionnaire about an experimental scenario for the purchase of Adidas sneakers. The results indicate that the discount influences impulsive buying and positive emotions mediate the relationship between identification with young people and impulse buying. There was also a propensity to appropriate the brand as an identity marker for Portuguese youth. Thus, in addition to the characteristics of products, group processes may be related to this purchasing behavior.

Keywords: impulse buying tendency; emotions; discount; youth; brand; social identity.

* Autor para dirigir correspondência.

Classificações JEL: M31; L67.

Como citar: Gonçalves, R., Lins, S. L. B., Aquino, S. D. de e Souza, L. E. C. de. (2021). 0 impulso da pertença: a influência da identidade social na compra por impulso de jovens Portugueses. Estudios Gerenciales, 37(161), 521-531. https://doi.org/10.18046/j.estger.2021.161.3977

DOI: https://doi.org/10.18046/j.estger.2021.161.3977

Recebido: 16- abr-2020

Aceito: $14-$ abr- 2021

Publicado: 22-out-2021 


\section{Introdução}

A compra por impulso é um tema de pesquisa relevante e pertinente para a investigação na área do comportamento do consumidor devido à sua complexidade e abrangente ocorrência nas mais variadas gamas de produtos (Kacen, Hess e Walker, 2012; Ramanathan e Menon, 2006; Rook, 1987; Santini, Ladeira, Vieira, Araujo e Sampaio, 2018; Vohs e Faber, 2007), especificamente pelo aumento das oportunidades de compra fornecidas pelas sociedades ocidentais modernas (Vohs e Faber, 2007).

As influências que estão por detrás de uma compra por impulso são amplas, podendo derivar, por exemplo, das emoções vivenciadas no ambiente de compra (Alencar de Farias, 2006), do desconto do produto (Liao, Shen e Chu, 2009) ou da marca (Tendai e Crispen, 2009). Entretanto é curioso entender as influências dos fatores grupais nas compras impulsivas, nomeadamente de jovens. Por que é que estes indivíduos compram por impulso? Será que, para além das características do produto como a marca e o preço, também são motivados a comprar simplesmente por pertencerem a um determinado grupo?

Nesse sentido, considerando que (1) as emoções no contexto de compra desempenham um papel marcante na tendência a comprar por impulso; (2) que o desconto é um fator importante no que toca a esse tipo de compra; (3) que jovens são considerados um grupo propenso para a compra impulsiva de produtos de marcas de moda; e (4) que o seu sentimento de pertença é muito relevante para esse comportamento, optou-se por realizar um estudo experimental que levasse em consideração essas variáveis. Assim, o presente estudo teve por objetivo analisar o efeito da identidade social, das emoções e da marca do produto na tendência de jovens para comprar sapatilhas ${ }^{1}$ por impulso.

Este artigo está estruturado em cinco secções. Seguindo a introdução, a segunda secção apresenta a fundamentação teórica, com uma revisão da literatura dividida em sete subsecções. A terceira secção apresenta o método utilizado para alcançá-lo. A quarta secção deste artigo apresenta os resultados. Por último, a quinta secção traz a discussão, as limitações do estudo, aplicações práticas e recomendação para futuros estudos.

\section{Fundamentação teórica}

\subsection{A compra por impulso}

Por compra por impulso entende-se um comportamento de compra súbito, atraente e hedónico, em que a rapidez da decisão de compra reduz a consideração de alternativas ou implicações futuras, acabando por

10 termo "sapatilhas" pode ter diferentes significados na língua portuguesa. Este manuscrito
está escrito em português europeu. Sapatilhas no português europeu tem o mesmo significado está escrito em português europe
de tênis no português brasileiro. se traduzir num impulso poderoso e persistente para comprar algo no imediato (Rook, 1987). O consumidor não tem, portanto, nenhum objetivo de pré-compra, nem necessidade de atender a qualquer exigência específica (Beatty e Ferrell, 1998). Essa definição surge no seguimento de estudos realizados por Rook (1987), onde consumidores admitiram que sentiram o produto a chamar por eles, quase exigindo que alguém os comprasse.

Stern (1962) forneceu um quadro básico para a compreensão da compra por impulso, classificando um comportamento de compra como (1) planeado, (2) não planeado ou (3) impulsivo. As compras planeadas envolvem pesquisa de informações demoradas, com tomada de decisão racional, enquanto que as não planeadas se referem a todas as decisões de compras feitas sem qualquer planeamento antecipado (Stern, 1962). Ainda de acordo com o autor, estudos iniciais indicavam que a compra por impulso era sinónimo de uma compra não planeada, mas a primeira é distinguida da segunda em termos de tomada de decisão rápida. Além de não ser planeada, uma compra por impulso também envolve experimentar um impulso súbito, forte e irresistível de comprar (Stern, 1962). É de ressalvar, ainda, que o comportamento de compra por impulso pode ser categorizado por "compra não planeada", porém, "compra não planeada" não pode ser sempre categorizada como "compra por impulso" (lyer, 1989; Kacen et al., 2012).

Vejamos o seguinte exemplo: estamos no supermercado a realizar as compras do mês com o auxílio da nossa lista de compras. Ao caminhar pelo corredor do leite, lembramo-nos de que precisamos de comprar mais embalagens para casa, apesar de este produto não estar na nossa lista de compras. Esse tipo de compra é não planeada, já que não tínhamos pensado em comprar leite inicialmente, mas não é uma compra por impulso. Esta componente de lembrete faz com que esta compra não planeada pudesse ser classificada como planeada caso o produto estivesse na nossa lista de compras (Kacen et al., 2012). Uma compra por impulso seria, por exemplo, caminhar pelo corredor do leite e, ao ver o produto, apesar de não estar na nossa lista de compras, vivenciar um desejo repentino de querer adquiri-lo e comprá-lo sem pensar.

Segundo Kacen e Lee (2002), o comportamento impulsivo é mais excitante e irresistível do que a compra planeada. Consequentemente, a compra por impulso relaciona-se com a alta ativação emocional, baixo controlo cognitivo e, ainda, por ser um comportamento espontâneo que se desenvolve quando se está perto de um objeto atraente (Sharma, Sivakumaran e Marshall, 2010). Os indivíduos que compram por impulso têm menor probabilidade de pensar cuidadosamente ou de considerar o impacto da compra antes de a fazer (Amos, Holmes, e Keneson, 2014).

São vários os termos atribuídos na literatura à compra por impulso e estes variam entre impulsividade 
na compra, comportamento de compra impulsiva e tendência de comprar por impulso (Amos et al., 2014; Lins, 2012; Youn e Faber, 2002). Neste trabalho, utilizarse-á o termo "tendência de comprar por impulso" (TCI) quando nos estivermos a referir ao impulso no momento da compra.

\subsection{Categorias da compra por impulso}

Stern (1962) classificou o comportamento de compra por impulso em quatro categorias: (1) a pura, (2) a relembrada, (3) a sugerida, e (4) a planeada. Mais tarde, Han, Morgan, Kotsiopulos e Kang-Park (1991) adaptaram estas categorias para o contexto de produtos de moda e desenvolveram quatro tipos de compra por impulso: (1) Compra por impulso planeada, que se caracteriza como uma compra que depende das condições propostas durante a venda, sendo que o consumidor decide na loja se efetua a compra ou não; (2) Compras por impulso relembradas, onde o consumidor se lembra de uma decisão ou experiência anterior que provoca a compra no local; (3) Sugestão ou compras por impulso orientadas para a moda, que se caracteriza por ser um tipo de compra que ocorre quando o consumidor vê um produto com um novo estilo, design ou tecido e decide comprá-lo; (4) Compra por impulso pura, que ocorre sem nenhum pensamento ou plano prévio para comprar. Os autores descreveram o impulso orientado para a moda como um tipo de impulso de sugestão, onde a compra é motivada por autossugestão para comprar um novo produto.

Perante o exposto, e considerando que o grupo em estudo são jovens Portugueses, procurou-se trabalhar a tendência a comprar por impulso (TCI) orientada para a moda de um produto cuja utilização thes fosse familiar. Assim, optou-se por um produto de moda de uma marca por eles reconhecido: as sapatilhas da marca Adidas. Mais à frente, essa escolha será explicitada (ver Estudo 1).

\subsection{As emoções na compra por impulso}

A compra por impulso é, muitas vezes, acompanhada por fortes reações afetivas, como reações de prazer e excitação (Rook, 1987; Amos et al., 2014) geradas nos indivíduos a partir da proximidade com o produto (Jones, Reynolds, Weun e Beatty, 2003). De acordo com Youn (2000), a compra por impulso compreende uma dimensão afetiva que se relaciona com as emoções e os estados de humor, e subdivide-se em: (1) irresistível desejo de comprar, (2) emoções positivas em relação à compra e (3) gestão do humor. Assim, entende-se que esta forma de comprar deriva de uma resposta emocional (Flight, Rountree e Beatty, 2012), que pode levar a emoções positivas ou negativas (Costa e Larán, 2003; Santini et al., 2018).
As emoções positivas desenvolvem um papel particularmente relevante quando se fala em produtos de moda, já que a compra por impulso é por elas influenciada (Mattila e Enz, 2002). 0 comportamento de compra por impulso orientado para a moda de jovens pode ser previsto por fatores emocionais (e.g., satisfação e excitação). Além disso, Park, Kim e Forney (2006) verificaram que as emoções positivas também aumentaram este tipo de compra.

Contudo, a resposta emocional depois de ver um produto específico ainda carece de estudo no âmbito da compreensão da sua influência na compra por impulso (Jones et al., 2003). Assim, neste estudo, procurar-se-á compreender as emoções no contexto de compra, ou seja, se há expressão de emoções positivas quando um consumidor está diante de um produto.

\subsection{0 preço como influente na compra por impulso}

0 consumidor é influenciado por diversos fatores na sua compra por impulso. Segundo Stern (1962), o preço baixo é um dos fatores que mais influencia e que provavelmente exerce um controlo mais direto na compra por impulso. Particularmente, os consumidores tendem a ser mais impulsivos durante a época de saldos ou de descontos (Virvilaite, Saladiene, e Bagdonaite, 2009).

Num estudo levado a cabo por Liao et al. (2009), os investigadores pretenderam identificar se as promoções nas vendas poderiam afetar a compra por impulso. Indicaram que esta estratégia, combinada com um produto apelativo, tem influências significativas na compra por impulso. Neste sentido, Mamuaya (2018) encontrou que a promoção de vendas afeta significativamente a compra impulsiva, o que quer dizer que quanto mais atraente é a promoção mais aumenta a compra por impulso. Tendai e Crispen (2009) também indicaram que fatores económicos, como o preço, têm uma maior probabilidade de influenciar a compra por impulso comparativamente com outros aspetos presentes numa loja, como a música ou a ventilação. Assim, o desconto será uma variável a ter em consideração neste estudo, por se revelar um fator importante no que toca à compra por impulso.

\subsection{A compra por impulso em jovens}

O comportamento de compra não é o mesmo para todas as idades. Os jovens são conhecidos como consumidores inconstantes e com capacidade para seguir tendências e produtos de moda (Noble, Haytko, e Phillips, 2009). Por este motivo, e por nos encontrarmos em sociedades de consumo, este público tornase aliciante nos estudos de compra. Investigações recentes (e.g., Lin e Chuang, 2005; Lins, Poeschl, e Eberhardt, 2016) indicam que a população jovem é mais propensa à compra por impulso, muito em parte porque é a mais interessada em novos produtos. Além disso, a publicidade está bastante direcionada para 
ela e a compra acaba por se traduzir numa forma de expressão da sua própria personalidade (Goldberg, Gorn, Peracchio, e Bamossy, 2003).

A relação geral entre a idade e a compra por impulso é inversa, i.e., com o aumento da idade, a compra por impulso tende a diminuir (Santini et al., 2018; Wood, 1998). Wood (1998) indicou que a probabilidade da compra por impulso é mais alta entre os 18 e os 39 anos, havendo, após essa faixa etária, um declínio na $\mathrm{TCl}$. Assim, o presente estudo focar-se-á em compreender os comportamentos de compra por impulso de jovens Portugueses, que tem entre 18 e 25 anos de idade.

\subsection{A compra por impulso e a marca}

A marca acaba por ilustrar a identidade grupal e o sentimento de pertença a grupos específicos (Jamison, 2006). Considerando que marcas e produtos são uma forma de expressão social, não é despropositado que os indivíduos sejam julgados face aos produtos e às marcas que utilizam (Wänke, 2009). À medida que as pessoas vão avançando nos seus ciclos de vida, as marcas tendem a tornar-se estilos de vida que refletem os interesses específicos de cada indivíduo (Jamison, 2006).

Um estudo realizado por Galhardo (2006) revelou que há uma preferência dos jovens por marcas de vestuário e calçado, mostrando, assim, a importância que a moda tem nesta faixa etária. Das marcas citadas, a Nike foi a mais evocada, tendo sido atribuídas a ela características como qualidade, ação e desporto. Seguiu-se a Adidas, com características como qualidade, conforto e comodidade, e design.

Lins et al. (2016) encontraram uma correlação positiva entre a importância atribuída à marca e a compra por impulso de adolescentes Portugueses, sugerindo que ter uma atitude positiva face a produtos de marca pode levar a comprar mais impulsivamente. Santos (2016) assume a utilização de uma marca pelos jovens como um "marcador identitário", significando que estes se estão a identificar com o seu grupo de pares ou de referência e utilizam a marca para pertencer a esse mesmo grupo. No presente estudo, será utilizada uma marca de calçado de moda específica e reconhecida pelo grupo em estudo: a marca Adidas. Assim, procurar-se-á verificar se a cotação da marca e a atitude favorável face à marca estão relacionadas com a compra por impulso.

\subsection{Identidade social}

Segundo Tajfel (1972), a identidade social é o conhecimento que um indivíduo tem da sua pertença a determinados grupos sociais e ao valor e significado emocional que sente perante esta associação aos mesmos. Elliott (1998) afirmou que a identidade própria se desenvolve simultaneamente com o desenvolvimento da identidade social, sendo que esta identidade própria deve ser validada por via da interação social.
Torna-se imprescindível haver uma distinção entre identidade e validação, já que, no que toca aos produtos de moda para o público jovem, por exemplo, a necessidade de definir uma identidade não tem obrigatoriamente a mesma importância do que a necessidade de aprovação social (Auty e Elliott, 2001). No entanto, a posse de materiais é um fator importante para as pessoas, uma vez que constituem símbolos tanto para a identidade pessoal como para a identidade social (Dittmar e Halliwell, 2007).

Enquanto indivíduos, pertencemos ou admiramos grupos diferentes, o que faz com que, muitas vezes, as nossas decisões de compra sejam feitas em função do desejo que temos em pertencer (Solomon, 2014). Uma pessoa que se defina enquanto membro de um grupo social específico assimilará frequentemente as principais características do grupo, atraindo a mesma para o interesse coletivo social também em termos de comportamento de compra (Langner, Hennigs, e Wiedmann, 2013). Esse aspeto foi evidenciado num estudo realizado com Portugueses sobre a compra de cachecóis de clubes futebol, onde se verificou que os indivíduos mais fortemente identificados com o seu clube tendiam a comprar o cachecol de forma mais impulsiva, comparativamente com os menos identificados (Teiga, 2019)

É de ressalvar, ainda, que a atitude face a uma marca é também explicada pela necessidade de que os indivíduos têm de aprovação social. Especificamente, os jovens não tentam ser exatamente como os seus amigos, mas procuram ser de uma forma que consigam obter a aprovação dos seus pares (Dittmar, 1992). Visto que o sentimento de pertença acaba por se traduzir num fator influenciador relevante no comportamento de compra, o presente estudo investiga a influência da identidade social de jovens na tendência a comprar produtos impulsivamente.

\section{Método}

A escolha pelo o uso do método experimental devese ao facto da presente pesquisa se propor a testar a direção das relações entre as variáveis citadas anteriormente, de modo a subsidiar com maior robustez quais as variáveis psicológicas e contextuais que são melhor preditoras da compra por impulso (Tonetto, Brust-Renck, e Stein, 2014). Este trabalho foi, assim, composto por dois estudos: um estudo piloto e um estudo experimental.

\subsection{Estudo 1}

Inicialmente foi realizado um estudo piloto com o objetivo de compreender qual a marca mais valorizada por jovens Portugueses e o respectivo produto dessa mesma marca. Foram inquiridos, por via de questionários online, 137 sujeitos de ambos os sexos (110 do sexo feminino e 27 do sexo masculino). Os par- 
ticipantes apresentavam idades compreendidas entre os 18 e os 25 anos $(M=21,75 ; D P=1,48)$. Aos inquiridos foi questionado quais as primeiras três marcas de sapatilhas, telemóveis e roupas que consideravam ser as mais valorizadas pelos jovens Portugueses. Os resultados encontram-se na Tabela 1.

Após a análise desses resultados, verificou-se que seria mais relevante aprofundar a investigação com a marca de sapatilhas ou com a marca de telemóveis, por serem as categorias que apresentaram maior frequência de respostas. No entanto, optou-se por realizar o estudo experimental com as marcas de sapatilhas, uma vez que o preço é relativamente mais baixo (e, portanto, mais acessívell do que o das marcas de telemóveis referenciadas.

\subsection{Estudo 2}

\subsubsection{Participantes}

Participaram no estudo 545 jovens Portugueses 1450 do sexo feminino e 94 do sexo masculino), com idade variando de 18 a 25 anos $(M=20,61, D P=2,09)$.

\subsubsection{Desenho experimental e procedimentos}

Foi adotado um delineamento fatorial entre participantes 2 (Desconto: sem desconto vs com desconto de $80 \%$ ) x 2 (Cotação da marca pelo grupo: mais cotada vs menos cotada), resultando em quatro condições distintas. A escolha por manipular o valor do desconto em detrimento de utilizar um preço justificase pelo entendimento de que preço é uma variável muito sensível. A percepção sobre o que é mais oneroso ou não varia muito de acordo com o indivíduo, as suas circunstancias financeiras, as atitude sobre a marca, a disponibilidade do produto, etc. Assim, ao atribuir ao produto um alto valor percentual de desconto, entende-se que a percepção de controlo por parte do consumidor é maior sobre a vantagem da compra, independentemente do valor a ser pago, e a sua necessidade de cognição para qualquer cálculo financeiro será menor.

Tabela 1. Marcas mais valorizadas pelos jovens Portugueses em função do tipo de produto

\begin{tabular}{lccccc}
\hline Tipologia & Marcas mais & \multicolumn{3}{c}{ Número de referências } & Total \\
\cline { 3 - 5 } & evocadas & Marca 1 & Marca 2 & Marca 3 & \\
\hline Sapatilhas & Adidas & 61 & 49 & 16 & 126 \\
& Nike & 45 & 39 & 35 & 119 \\
Telemóveis & New Balance & 23 & 36 & 33 & 92 \\
& Apple & 115 & 12 & 5 & 132 \\
& Samsung & 14 & 111 & 9 & 134 \\
Roupas & Huawei & 3 & 8 & 70 & 81 \\
& Zara & 60 & 20 & 15 & 95 \\
& Levi's & 22 & 5 & 9 & 36 \\
& Nike & 8 & 3 & 4 & 15 \\
\hline
\end{tabular}

Fonte: elaboração própria.
A amostra foi recolhida entre janeiro e março de 2018, por via de um questionário online, cujo link foi disponibilizado por e-mail e por meio da rede social Facebook. 0 questionário apresentava quatro cenários diferentes, um para cada condição. 0 que diferenciava os cenários eram a cotação da marca (mais cotada/ menos cotadal e a existência ou ausência de desconto.

\section{- Cenário experimental}

Há muito que se sabe que a marca Adidas está extremamente presente no quotidiano dos jovens Portugueses. Contudo, um estudo recente levado a cabo pelo Instituto da Juventude Portuguesa, indicou que a marca Adidas é a mais/menos cotada pelos jovens dos 18 aos 25 anos de idade de todo o território nacional. Os participantes deste estudo realizado no segundo trimestre de 2017, indicaram que a marca Adidas é/ não é a sua marca de eleição, ficando a cotação acima/abaixo de outra marcas bem conhecidas como a Nike ou a New Balance. [Retirado do relatório anual de 2017 do Instituto da Juventude Portuguesa]*

Imagine-se na seguinte situação. É importante que tente recriar mentalmente a situação como se a estivesse efetivamente a vivenciar.

Está a passear num centro comercial. A dada altura, passa em frente a uma loja e pára para ver as novidades da montra. Repara que nos pés de um dos manequins da montra estão umas sapatilhas da marca Adidas. A marca destas sapatilhas é a mais/menos valorizada pelos jovens Portugueses. (Neste momento, está com $80 \%$ de desconto/ Não se fazia referência a existência de um desconto.)

*Essa referência foi utilizada apenas para este estudo

Os cenários foram lançados aleatoriamente pelo servidor e cada participante foi incluído em apenas uma condição experimental. Os participantes distribuiramse da seguinte forma pelas quatro condições (Tabela 2).

Os participantes reponderam previamente a um consentimento informado, garantindo o anonimato e confidencialidade das respostas, bem como clarificando a sua participação como sendo voluntária. Após a obtenção da amostra, foram contabilizados os participantes que estavam familiarizados com a marca e os que responderam corretamente à manipulation check. No final, os participantes encontravam um debriefing sobre o estudo, juntamente com um endereço de email para contacto, bem como agradecimentos pela participação.

Tabela 2. Distribuição dos participantes pelas várias condições do cenário experimental

\begin{tabular}{lccc}
\hline Desconto & \multicolumn{2}{c}{ Cotação da marca } & \multirow{2}{*}{ Total } \\
\cline { 2 - 3 } & Positiva & Negativa & \\
\hline Sem desconto & 140 & 137 & 277 \\
Com 80\% de desconto & 148 & 120 & 268 \\
Total & 288 & 257 & 545 \\
\hline
\end{tabular}

Fonte: elaboração própria. 


\subsubsection{Variáveis dependentes}

Tendência de comprar por impulso no contexto (TCl-Contexto). Para medir a tendência de compra por impulso no contexto de compra, foi utilizada a seguinte escala, adaptada da escala de Rook e Fisher (1995), que contempla sete questões (“Eu ficaria com vontade de comprar estas sapatilhas da marca Adidas no impulso do momento"; "Eu ficaria com vontade de comprar estas sapatilhas da marca Adidas espontaneamente"; "Eu ficaria simplesmente com vontade de comprar estas sapatilhas da marca Adidas"; "Eu ficaria com vontade de comprar estas sapatilhas da marca Adidas sem pensar"; "Eu ficaria com vontade de comprar estas sapatilhas da marca Adidas assim que as visse"; "Eu ficaria com vontade de comprar estas sapatilhas da marca Adidas e pensaria sobre isto depois"; "Eu ficaria com vontade de comprar estas sapatilhas da marca Adidas 0 mais rápido possível"; $\alpha=0,91$ ), sendo avaliada numa escala de Likert de 5 pontos, sendo que 1 ="discordo totalmente" e 5 = "concordo totalmente".

Emoções. A intensidade das emoções positivas lempolgado/a, contente e animado/a, $\alpha=0,93$ ), e das emoções negativas (incomodado/a, frustrado/a e triste, $\alpha=0,93$ ) dos participantes face ao cenário apresentado foi medida através de uma escala de Likert de 5 pontos (sendo que 1 = "Nada" e 5 = "Extremamente").

Familiaridade com a marca. A familiaridade com a marca foi verificada através de duas questões: "Conhece a marca Adidas?" (Sim; Não) e "Conhece as sapatilhas da marca Adidas?" (Sim; Não).

Manipulation check. Com intenção de validar as respostas dos participantes, foram criadas três questões finais: "Qual foi o intervalo de idades dos participantes do estudo levado a cabo pelo Instituto da Juventude Portuguesa?" 19 a 12 anos; 18 a 25 anos; 47 a 55 anos); "Segundo o estudo do Instituto já Juventude Portuguesa, a marca Adidas está mais cotada do que as marcas Nike e New Balance?" (Sim; Não; Não sei); e "No cenário descrito, as sapatilhas da marca Adidas estavam com algum tipo de desconto?" (Não; Sim, 30\%; Sim, 80\%; Não seil.

\subsubsection{Outras medidas}

Identificação com os jovens Portugueses. A escala de identificação com os jovens Portugueses foi adaptada da escala brasileira desenvolvida por Lins e Borsa (2014). É composta por cinco questões, avaliadas numa escala de Likert de 5 pontos, sendo que 1 = "discordo totalmente" e 5 = "concordo totalmente" ("Ser um/a jovem Português/Portuguesa é importante para mim"; "Gosto de ser um/a jovem Português/Portuguesa"; "Identifico-me com os/as jovens Portugueses/Portuguesas em geral"; "Orgulho-me em ser um/a jovem Português/Portuguesa"; "Sinto satisfação em pensar que sou um/a jovem Português/Portuguesa"; $\alpha=0,92$ ).
Atitude face à marca de sapatilhas Adidas. De forma a medir a atitude que os participantes do estudo têm face às sapatilhas da marca Adidas, foi usada uma escala de 5 pontos com quatro pares de adjetivos, que completavam a afirmação "As sapatilhas da marca Adidas são:" (desfavoráveis/favoráveis; desagradáveis/ agradáveis; indesejáveis/desejáveis; más/boas; $\alpha=0,91$ ).

Tendência de comprar por impulso (TCI). Para medir o impulso na compra dos/das participantes foram utilizados três itens, avaliados numa escala de Likert de 5 pontos, sendo que 1 = "discordo totalmente" e 5 = "concordo totalmente" ("Eu sou impulsivo/a quando estou a comprar"; "Eu costumo comprar coisas sem pensar"; "Às vezes fico com vontade de comprar no impulso do momento", $\alpha=0,81$ ).

As variáveis apresentadas estão sintetizadas na tabela seguinte (Tabela 3), com os respetivos valores de média e desvio padrão.

Tabela 3. Variáveis em estudo

\begin{tabular}{llc}
\hline $\begin{array}{l}\text { Grupo de } \\
\text { Variáveis }\end{array}$ & Variáveis em estudo & M (DP) \\
\hline $\begin{array}{l}\text { Variáveis } \\
\text { dependentes }\end{array}$ & $\begin{array}{l}\text { Tendência de Comprar por Impulso no } \\
\text { contexto (TCl-Contexto) }\end{array}$ & $2,38(0,98)$ \\
& Emoções positivas & $3,30(1,06)$ \\
& Emoções negativas & $1,40(0,74)$ \\
Outras & Identificação com os jovens Portugueses & $3,89(0,82)$ \\
medidas & Atitude face à marca de sapatilhas Adidas & $4,11(0,76)$ \\
& Tendência de Comprar por Impulso (TCI) & $2,37(0,91)$ \\
\hline
\end{tabular}

Fonte: elaboração própria.

\section{Resultados}

Inicialmente, foi realizada uma ANCOVA para a verificação do impacto da cotação e desconto sobre a tendência de comprar por impulso (TCI). Em seguida, foram realizadas correlações de Pearson a fim de verificar a presença e a força das relações entre as variáveis. Também foi realizada uma análise de regressão, com o objetivo de identificar as variáveis que predizem diretamente a TCl. Por fim, apresentamos uma análise de mediação das Emoções positivas na relação entre Identificação com os jovens Portugueses e a TClContexto em todas as condições experimentais. Tais análises e resultados estão detalhados nesta secção, a seguir:

- Efeito da cotação e do desconto. De forma a verificar se a cotação da marca e o desconto teriam um impacto na tendência dos participantes a comprar por impulso, realizou-se uma Análise de Covariância, ANCOVA (Cotação x Desconto), controlando a TCl. Verificou-se apenas um efeito principal do Desconto na TCl-Contexto, $F(1,545)=32,24, \quad p<0,001, \eta^{2}=0,06$, sendo que a tendência para comprar por impulso é maior quando o produto está com desconto $(M=2,58$, $D P=1,01)$, comparativamente a quando este não está com desconto $(M=2,18, D P=0,91)$. 
- Relações entre as variáveis do estudo. Partindo da análise das correlações $r$ de Pearson (Tabela 4), verificaram-se correlações positivas e fortes entre as Emoções positivas e a TCl-Contexto, em todas as quatro condições experimentais. Assim, quanto mais emoções positivas forem sentidas pelo indivíduo face ao cenário de compra, maior é a tendência a comprar por impulso. Relativamente às Emoções negativas, existe apenas uma correlação negativa na condição Cotação negativa x Com $80 \%$ de desconto, o que significa que à medida que aumentam as emoções negativas vivenciadas no contexto em que o produto não é muito cotado e está com $80 \%$ de desconto, diminui a tendência a comprar por impulso.

Ademais, as correlações positivas entre a atitude face à marca de sapatilhas Adidas e a TCl-Contexto mostram que quanto mais favorável é a atitude dos inquiridos face às sapatilhas da marca Adidas, maior é a sua tendência a comprar por impulso. Essa correlação é mais forte quando o produto tem uma cotação positiva e está com $80 \%$ de desconto e mais fraca quando o produto está menos cotado e tem $80 \%$ de desconto.

Os resultados também indicam uma correlação positiva entre a Identificação com os jovens Portugueses e a TCl-Contexto, em todos os cenários. Portanto, quanto mais identificado o respondente está com os jovens Portugueses, maior é a tendência a comprar as sapatilhas da marca Adidas por impulso. Por fim, a $\mathrm{TCl}$ e a $\mathrm{TCl}$-Contexto estão positivamente correlacionadas em todas as condições, de forma que, quanto maior a tendência da pessoa para comprar por impulso, maior é também a sua tendência a comprar por impulso as sapatilhas da marca Adidas. Contudo, essa correlação é mais fraca quando as sapatilhas estão menos cotadas e sem desconto.

Adicionalmente, foi realizada uma regressão linear múltipla (Método Enter) com o objetivo de identificar quais as variáveis que predizem diretamente a TClContexto (Tabela 5). Nesta regressão, as variáveis Cotação $10=$ Cotação Positiva; $1=$ Cotação Negatival e Desconto $10=$ Sem desconto; $1=$ Com $80 \%$ de descontol foram transformadas em dummy variables. Os preditores explicam $46,4 \%$ da variável dependente, $\mathrm{R}^{2}{ }_{\mathrm{aj}}=0,464, F(6,545)=79.41, p<0,001$. Pela análise, verifica-se que são as Emoções positivas que tem maior impacto na TCl-Contexto $(\beta=0,54, p<0,001)$, seguido do Desconto $(\beta=0,23, \quad p<0,001)$, da Atitude face à marca de sapatilhas Adidas $(\beta=0,15 ; p<0,001)$, e da Identificação com os jovens Portugueses ( $\beta=0,06$; $p=0,092$ ), este com um valor de $p$ marginalmente significativo.

Uma vez que a Identificação com os jovens Portugueses apresenta correlações positivas com a TClContexto, e pensando sobre o forte papel das emoções no comportamento de compra (Park et al., 2006), explorou-se a possibilidade de o efeito da identificação com os jovens Portugueses na TCl-Contexto ser mediado pelas Emoções positivas (Figura 1). Assim, recorreu-se ao macro PROCESS (Modelo 4; Hayes, 2013).

Verifica-se um efeito mediador total das Emoções positivas na relação entre Identificação com os jovens Portugueses e a TCl-Contexto em todas as condições experimentais, explicando de $39 \%$ a $50 \%$ da variância. Deste modo, a ausência de relação entre a identificação com os jovens e a $\mathrm{TCl}$-Contexto na análise de regressão múltipla apresentada anteriormente faz sentido, uma vez que esse efeito não é direto, mas sim mediado pelas emoções positivas. Isso significa que a identificação com os jovens Portugueses evoca emoções positivas no contexto de compra que, por sua vez, conduzem a uma maior tendência a comprar por impulso as sapatilhas da marca Adidas. Importa destacar que as emoções positivas desempenham um papel mais forte na condição quando as sapatilhas estão positivamente cotadas e com $80 \%$ de desconto (Tabela 6).

Tabela 4. Correlações entre as variáveis e a $\mathrm{TCl}$-contexto por condição

\begin{tabular}{lcccc}
\hline Variáveis em estudo & \multicolumn{3}{c}{ Cotação da marca } \\
\cline { 2 - 5 } & \multicolumn{2}{c}{ Positiva } & \multicolumn{2}{c}{ Negativa } \\
\cline { 2 - 5 } & $\begin{array}{c}\text { Sem } \\
\text { desconto }\end{array}$ & $\begin{array}{c}\text { Com } \\
80 \% \\
\text { desconto }\end{array}$ & $\begin{array}{c}\text { Sem } \\
\text { desconto }\end{array}$ & $\begin{array}{c}\text { Com } \\
80 \% \\
\text { desconto }\end{array}$ \\
\hline Emoções positivas & $0,64^{* *}$ & $0,71^{* *}$ & $0,62^{* *}$ & $0,62^{* *}$ \\
Emoções negativas & $-0,14$ & 0,02 & $-0,15$ & $-0,20^{*}$ \\
$\begin{array}{l}\text { Identificação com os } \\
\text { jovens Portugueses/as }\end{array}$ & $0,26^{* *}$ & $0,26^{* *}$ & $0,22^{* *}$ & $0,28^{*}$ \\
$\begin{array}{l}\text { Atitude face à marca de } \\
\text { sapatilhas Adidas }\end{array}$ & $0,47^{* *}$ & $0,56^{* *}$ & $0,45^{* *}$ & $0,34^{* *}$ \\
$\begin{array}{l}\text { Tendência de comprar } \\
\text { por impulso }\end{array}$ & $0,27^{* *}$ & $0,42^{* *}$ & $0,18^{*}$ & $0,35^{* *}$ \\
\hline
\end{tabular}

Nota. ${ }^{* *} p<0,01 ;{ }^{*} p<0,05$

Fonte: elaboração própria.

Tabela 5. Regressão linear múltipla das variáveis com a TCl-contexto (método enter)

\begin{tabular}{lccc}
\hline Variáveis em estudo & \multicolumn{3}{c}{ Estatística } \\
\cline { 2 - 5 } & $\mathrm{B}$ & $\mathrm{t}$ & $\mathrm{p}$ \\
\hline Cotação da marca & 0,02 & 0,72 & 0,472 \\
Desconto & 0,23 & 7,28 & $<0,001$ \\
Emoções positivas & 0,54 & 14,43 & $<0,001$ \\
Emoções negativas & 0,04 & 1,13 & 0,259 \\
Identificação com os jovens Portugueses & 0,06 & 1,69 & 0,092 \\
Atitude face à marca de sapatilhas Adidas & 0,15 & 3,97 & $<0,001$ \\
Coeficiente de correlação múltipla & \multicolumn{4}{c}{0,67} \\
\% Variabilidade explicada & \multicolumn{4}{c}{$46,4 \%$} \\
Significância da amostra & \multicolumn{4}{c}{$F_{6,545}=79,41$} \\
p< & \multicolumn{4}{c}{$<0,001$} \\
\hline
\end{tabular}

Fonte: elaboração própria. 


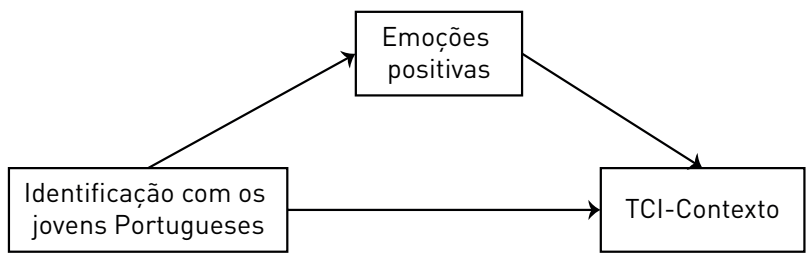

Figura 1. Modelo das emoções positivas como mediador entre a identificação com os jovens Portugueses e a TCl-contexto

Fonte: elaboração própria.

\section{Discussão e conclusão}

Neste estudo pretendeu-se analisar o efeito da identidade social, das emoções e da marca do produto na tendência de jovens para comprar sapatilhas por impulso. Para isso, considerou-se a identidade social dos jovens, bem como a influência das emoções positivas sentidas perante o cenário de compra e da atitude face à marca.

Debruçando-nos sobre os principais resultados, a Análise de Covariância demonstra uma influência significativa do desconto na tendência a comprar por impulso (TCI), pois tal tendência é maior quando o produto está com desconto. 0 valor dos produtos evoca sempre a pré-disponibilidade financeira das pessoas, bem como a sua percepção individual sobre o que é oneroso ou oportunamente barato para ser adquirido. Acredita-se que o desconto promocional estimula - consumidor a realizar a compra de forma menos conscienciosa, porque transmite ao comprador maior sensação de poder de compra e o suposto conforto financeiro de adquirir um produto por um valor mais baixo, melhorando a percepção sobre o custobenefício.

0 desconto desempenha um papel racional e emocional na compra, já que, por um lado, permite ao consumidor racionalizar o desejo e minimizar o risco financeiro associado à compra e, por outro lado, controla as emoções negativas que podem levar os consumidores a resistir a esse desejo (McGoldrick, Betts e Keeling, 1999), ou seja, o desconto e a percepção de um preço baixo podem criar emoções positivas nos consumidores para levá-los à compra por impulso (Amara e Kchaou, 2014).

Considerando que o valor de desconto aplicado no estudo experimental foi propositalmente alto, entende-se que a percepção de controlo por parte dos participantes foi elevada, baixando a sua necessidade de cognição a respeito do cálculo financeiro. Porém, em ambientes naturais de compra, não é comum encontrar ofertas de desconto tão altas. Assim, estudos futuros podem ocultar o valor percentual e manipular apenas a informação de que um desconto terá sido dado, pois entende-se que apenas esse estímulo já pode gerar emoções positivas em relação à aquisição do produto.

Adicionalmente, as análises de correlação e de regressão confirmam que as emoções e a compra por impulso estão diretamente ligadas, uma vez que sen- timentos como alegria, amor e fantasia encorajam a compra que não estava planeada (Jhawar e Kushwaha, 2018) e esse aspeto foi evidente na análise dos resultados. Há, portanto, um papel importante das emoções, principalmente positivas, na compra por impulso, que acaba por ser mais emocional do que racional (Masouleh, Pazhang e Moradi, 2012), já que quanto mais emoções positivas os jovens tendem a ter, maior é a $\mathrm{TCl}$. Estes resultados corroboram com estudos que relatam que a compra por impulso de produtos de moda é influenciada pelas emoções positivas do comprador no ato de compra (Mattila e Enz, 2002); bem como reforça a ideia de que a emoção positiva desempenha um papel importante no comportamento de compra por impulso, como previsto (Park e Kim, 2008).

Em contrapartida, os resultados revelaram que se forem sentidas emoções negativas, a tendência de compra por impulso tende a inverter-se, no contexto de cotação da marca negativa com $80 \%$ de desconto. Isso reforça o poder do viés de ancoragem que faz com que as pessoas se baseiem em informações iniciais ao tomar decisões (Furnham e Boo, 2011). Durante a tomada de decisão de compra, conhecer o preço anterior, e calcular a grande diferença que o desconto provoca no valor final da compra, ancora os julgamentos subsequentes nas informações iniciais sobre a efetivação da compra, fazendo com que a ancoragem torne a compra mais irresistível. Isso torna-se particularmente relevante para a forma como as marcas comunicam as suas campanhas com desconto: é importante garantir que sejam suscitadas emoções positivas no cliente face aos contextos de compra, e não emoções negativas, de maneira a que pessoas adquiram produtos da marca.

Quando houve uma identificação com os jovens Portugueses, houve também uma maior tendência a comprar por impulso. Sabe-se que alguns produtos constituem símbolos para a identidade social (Dittmar e Halliwell, 2007), e que indivíduos mais fortemente identificados com o seu grupo tendem a comprar mais impulsivamente produtos que realcem essa identificação (Teiga, 2019). Assim, supõe-se que uma identidade social forte se associa a uma perceção de mais emoções positivas num contexto de grupo e, portanto, suscita emoções positivas que podem levar a uma maior $\mathrm{TCl}$, dependendo do produto.

Um aspeto interessante destes resultados é que estes sugerem que existe uma apropriação da marca como identitária dos jovens Portugueses. Assim, a marca Adidas parece apresentar-se como um "marcador identitário", tendendo a assumir-se como uma marca representativa deste grupo de jovens, que a vêm como "sua". De acordo com Jamison (2006), produtos de determinadas marcas trazem poder e prestígio, já que simbolizam a identidade de um grupo e o sentimento de pertença ao mesmo. 
Tabela 6. Valores do modelo de mediação para as diferentes condições experimentais

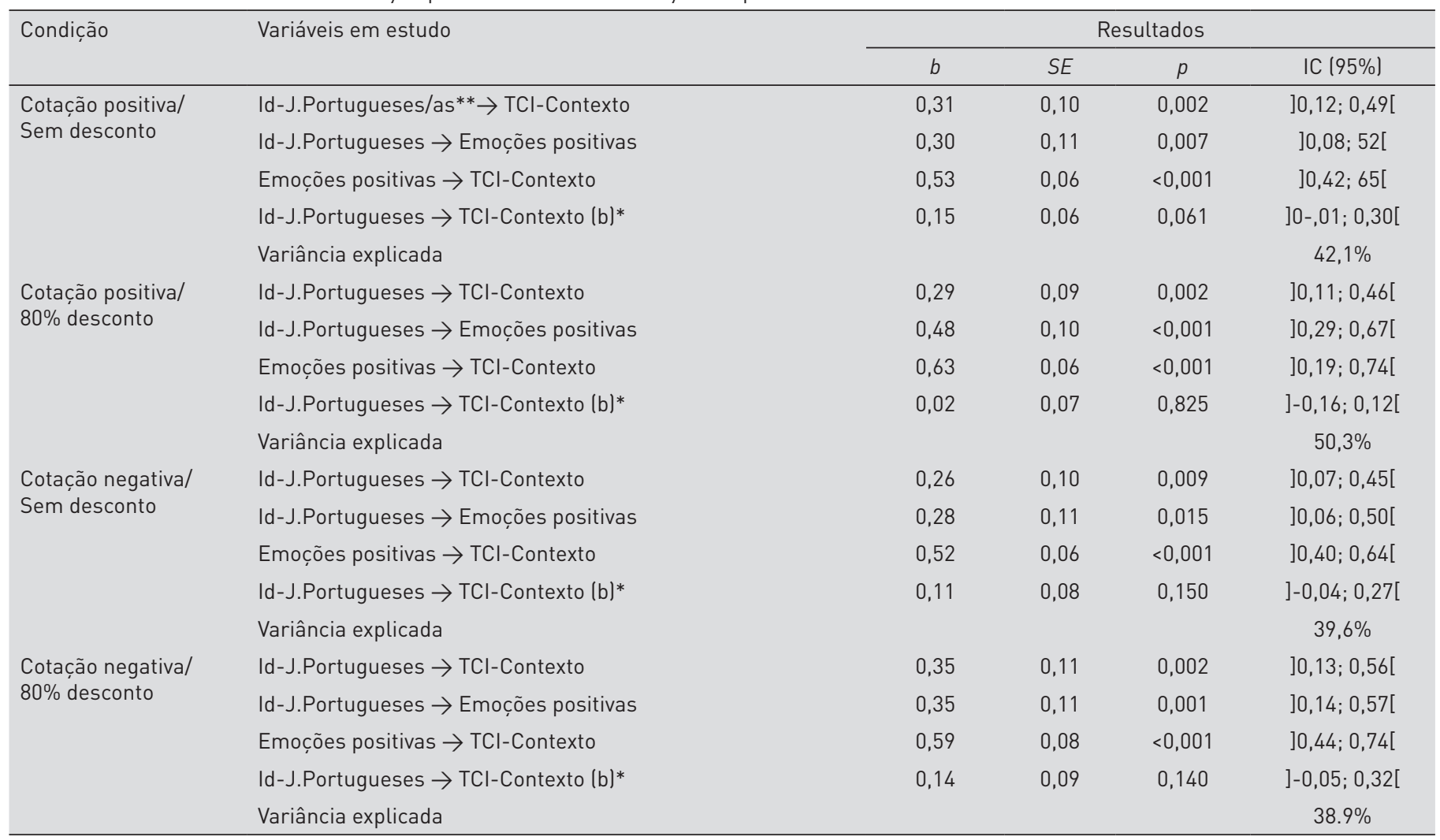

Nota. *Efeito direto, i.e., coeficiente de regressão após controlar o efeito da variável mediadora. ${ }^{* *}$ Identificação com os jovens Portugueses/as.

Fonte: elaboração própria.

A conformidade com expectativas dos outros às próprias decisões de compra indica uma tendência de ser suscetível a normas sociais e isso impacta positivamente o comportamento de compra por impulso (Aquino, Natividade, e Lins, 2019; Lin e Chen, 2012; Taute e McQuitty, 2004). Naturalmente, há uma evidência da tendência dos consumidores em seguir os seus pares no que toca à marca a escolher, como se confiassem mais nos seus círculos sociais do que nas afirmações das próprias marcas (Kotler, Kartajaya e Setiawan, 2017). Assim, e uma vez que a Adidas foi considerada uma marca valorizada pelo grupo de pertença (i.e. os jovens Portugueses), não é surpreendente que os resultados deste estudo tenham mostrado que quanto maior a atitude face a esta, maior é a tendência a comprar por impulso, nomeadamente quando o produto está com desconto.

Com este estudo, compreendeu-se, ainda, que quanto maior a identificação com os jovens portugueses, maior são as emoções positivas sentidas diante de um produto valorizado por estes, levando a uma maior tendência de compra por impulso. Isso confirmou-se ao analisar a mediação das Emoções positivas na relação entre Identificação com jovens Portugueses e TCl-Contexto. A marca acabou por se revelar importante, já que é evidenciada uma tendência à apropriação da mesma para o grupo, assim como o desconto, que despoletou ainda mais - impulso de comprar. Contudo, as razões pelas quais as pessoas compram por impulso estão longe de estar completamente aprofundadas, merecendo este tema uma abordagem mais alargada, dado que é um comportamento bastante comum numa elevada percentagem da população (Lins et al., 2016).

Relativamente ao produto a ser utilizado, vale ressalvar como recomendação futura a atenção dedicada à escolha da marca, considerando questões éticas e de sustentabilidade a ela associadas, uma vez que a sociedade contemporânea está atenta a estes tópicos. Ter um certo grau de conhecimento sobre a marca pode ser relevante, pois ela pode estar em evidência por razões positivas, neutras ou até mesmo negativas.

Seria, também, aliciante verificar qual o comportamento dos inquiridos em compras online com outros produtos de moda e entender se haveria diferenças comparativamente com as compras em lojas físicas. Pensando no produto utilizado, as sapatilhas, apesar do custo mais acessível e de mais frequentemente compradas, a preocupação com questões socioeconómicas seria igualmente pertinente para estudos futuros, considerando que se 
trata de uma faixa etária cujo poder de compra pode não ser muito elevado. Da mesma forma, dadas as características variadas da compra por impulso, mensurar a tendência de compra impulsiva por meio de um estudo em redes sociais pode ser interessante no futuro. 0 método escolhido de questionário autoresponsivo pode ser considerado uma limitação deste estudo, ainda que seja também um diferencial e um avanço para a temática principal.

Neste estudo, foi utilizado como público alvo jovens Portugueses. Porém, ao longo de toda a revisão literária, encontrou-se que os adolescentes são bastante suscetíveis à influência social por parte dos seus pares (Lin e Chen, 2012; Lins, 2013) e é na adolescência que o consumo mostra ter um papel mais importante na criação da identidade social (Lins e Poeschl, 2015). O viés amostral pode ser entendido como uma limitação, considerando não só a nacionalidade específica, como também o número elevado de participantes do sexo feminino - um viés recorrente nas pesquisas com amostras aleatórias por conveniência. Apesar disso, as análises feitas e as discussões apresentadas consideram a diminuição do erro amostral e a pertinência dos resultados. Desta maneira, seria interessante replicar a investigação também com outros grupos etários, culturais e com a divisão mais igualitária entre participantes de ambos os sexos.

Entende-se que este estudo pode trazer insights interessantes na gestão dos produtos e no conhecimento dos consumidores, tanto para profissionais de Marketing, como para investigadores de Psicologia Social e do Consumidor, considerando a temática interdisciplinar das variáveis estudadas. Uma vez que a identidade social suscita emoções positivas quando se trata de um produto importante e valorizado pelo grupo de pertença, as marcas podem investir em nichos de mercado e grupo de pessoas específicos para o seu grupo alvo, de forma a conduzir a uma emotividade favorável à compra por impulso.

Os descontos aliciantes podem suscitar, também, processos de compra por impulso, como se pode comprovar em algumas investigações que acreditam que as campanhas promocionais ou as exibições estratégicas de produtos que expressam valores materialistas ou hedónicos provavelmente gerarão compras por impulso (Santini et al., 2018). Ressalvase, contudo, a importância de que as campanhas sejam conscientes e éticas, e que o acesso ao autoconhecimento favoreça o consumo equilibrado e ajustado às necessidades e possibilidades de cada pessoa.

\section{Conflito de interesses}

Os autores declaram não haver conflito de interesses.

\section{Referências}

Alencar de Farias, S. (2006). Atmosfera de loja on-line: o impacto do ambiente virtual na satisfação do consumidor e na atitude para com a compra. Revista de Administração - RAUSP, 42(1), 31-41.

Amara, R., \& Kchaou, A. (2014). The role of sales promotion in inducing impulse purchases. International Journal of Management Excellence, 3(1), 362-372. https://doi.org/10.17722/ijme.v3i1.144

Amos, C., Holmes, G., \& Keneson, W. (2014). Ameta-analysis of consumer impulse buying. Journal of Retailing and Consumer Services, 21(2), 86-97. https://doi.org/10.1016/j.jretconser.2013.11.004

Aquino, S. D., Natividade, J. C., \& Lins, S. L. B (2019). Sua personalidade vai ao shopping? Relações entre personalidade e a compra por impulso. Psico, 50(4), 31905.

https://doi.org/10.15448/1980-8623.2019.4.31905

Auty, S. G., \& Elliott, R. (2001). Being like or being liked: identity vs. approval in a social context. Advances in Consumer Research, 28(1), 235-241.

Beatty, S., \& Ferrell, M. (1998). Impulse buying: Modeling its precursors. Journal of Retailing, 74(2), 169-191. https://doi.org/10.1016/S0022-4359(98)90009-4

Costa, F., \& Larán, J. (2003). A compra por impulso em ambientes online. Revista de Administração de Empresas, 43(4), 36-47. https://doi.org/10.1590/S0034-75902003000400004

Dittmar, H. (1992). The social psychology of material possessions: To have is to be. New York: Harvester Wheatsheaf and St Martin's Press.

Dittmar, H., \& Halliwell, E. (2007). Consumer culture, identity and wellbeing. Hove: Psychology.

Elliott, R. (1998). A model of emotion-driven choice. Journal of Marketing Management, 14(1-3), 95-108. https://doi.org/10.1362/026725798784959408

Flight, R., Rountree, M., \& Beatty, S. (2012). Feeling the urge: affect in impulsive and compulsive buying. Journal of Marketing Theory and Practice, 20(4), 453-465. https://doi.org/10.2753/MTP1069-6679200407

Furnham, A., \& Boo, H. C. (2011). A literature review of the anchoring effect. The journal of socio-economics, 40(1), 35-42. https://doi.org/10.1016/j.socec.2010.10.008

Galhardo, A. (2006). Marcas com que me identifico - o ponto de vista de um grupo de jovens consumidores. In Cardoso, P., Gaio, S., \& Seoane, J., Jovens, Marcas e Estilos de Vida (1st ed.). Porto: Edições Universidade Fernando Pessoa.

Goldberg, M., Gorn, G., Peracchio, L., \& Bamossy, G. (2003). Understanding materialism among youth. Journal of Consumer Psychology, 13, 278-288. https://doi.org/10.1207/s15327663jcp1303_09

Han, Y., Morgan, G., Kotsiopulos, A., \& Kang-Park, J. (1991). Impulse buying behavior of apparel purchasers. Clothing and Textiles Research Journal, 9(3), 15-21. https://doi.org/10.1177/0887302x9100900303

Hayes, A. (2013). Introduction to mediation, moderation, and conditional process analysis: a regression-based approach. New York: The Guilford Press.

lyer, E. S. (1989). Unplanned purchasing: Knowledge of shopping environment and time pressure. Journal of Retailing, 65(1), 40-57.

Jamison, D. (2006). Idols of the tribe: brand veneration, group identity, and the impact of school uniform policies. Academy of Marketing Studies Journal, 10(1), 19-42.

Jhawar, N., \& Kushwaha, V. (2018). In-store shopping environment and impulsive buying with special reference to indoor city. The IUP Journal of Marketing Management, 17(1), 25-37.

Jones, A., Reynolds, E., Weun, S., \& Beatty, E. (2003). The productspecific nature of impulse buying tendency. Journal of Business Research, 56(7), 505-511. https://doi.org/10.1016/s0148-2963(01)00250-8

Kacen, J., \& Lee, J. (2002). The influence of culture on consumer impulsive buying behavior. Journal of Consumer Psychology, 12(2), 163-176. https://doi.org/10.1207/s15327663jcp1202_08 
Kacen, J., Hess, J., \& Walker, D. (2012). Spontaneous selection: The influence of product and retailing factors on consumer impulse purchases. Journal of Retailing and Consumer Services, 19(6), 578588. https://doi.org/10.1016/j.jretconser.2012.07.003

Kotler, P., Kartajaya, H., \& Setiawan, I. (2017). Marketing 4.0 - Mudança do tradicional para o digital (1st ed.). Coimbra: Conjuntura Actual Editora.

Langner, S., Hennigs, N., \& Wiedmann, K. (2013). Social persuasion: targeting social identities through social influencers. Journal of Consumer Marketing, 30(1), 31-49. https://doi.org/10.1108/07363761311290821

Liao, S., Shen, Y., \& Chu, C. (2009). The effects of sales promotion strategy, product appeal and consumer traits on reminder impulse buying behaviour. International Journal of Consumer Studies, 33(3), 274-284. https://doi.org/10.1111/j.1470-6431.2009.00770

Lin, C., \& Chuang, S. (2005). The effect of individual differences on adolescents' impulsive buying behavior. Adolescence, 40(159), 551558.

Lin, Y., \& Chen, C. (2012). Adolescents' impulse buying: susceptibility to interpersonal influence and fear of negative evaluation. Social Behavior and Personality, 40(3), 353-358. https://doi.org/10.2224/sbp.20t2.40.3.353

Lins, S. (2012). Life satisfaction: Impulsive buying behaviour and gender. In P. Zahrádka \& R. Sedláková (Eds.), New perspectives on consumer culture theory and research (pp. 164-178). Newcastle: Cambridge Scholars Publishing.

Lins, S. (2013). Consumo, contexto socioeconómico e compra por impulso em adolescentes brasileiros e portugueses. (Ph.D). Faculdade de Psicologia e de Ciências da Educação da Universidade do Porto.

Lins, S., \& Borsa, J. (2014). Identidade social, saúde mental e avaliação dos impactos da Copa do Mundo FIFA 2014. Psicologia e Saber Social, 3(1). https://doi.org/10.12957/psi.saber.soc.2014.12208

Lins, S., \& Poeschl, G. (2015). Gastar dinheiro em roupas no shopping: os significados de "comprar" para adolescentes brasileiros e portugueses. Temas em Psicologia, 23(2), 355-369. https://doi.org/10.9788/tp2015.2-06

Lins, S., Poeschl, G., \& Eberhardt, A. (2016). Identificando os factores de influência da compra por impulso em adolescentes Portugueses. Análise Psicológica, 34(2), 147-163. https://doi.org/10.14417/ap.920

Mamuaya, N. (2018). The effect of sales promotion and store atmosphere on hedonic shopping motivation and impulsive buying behavior in hypermart manado city. Derema Jurnal Manajemen, 13(1). http://dx.doi.org/10.19166/derema.v13i1.785

Masouleh, S., Pazhang, M., \& Moradi, J. (2012). What is impulse buying? An analytical network processing framework for prioritizing factors affecting impulse buying. Management Science Letters, 2(4), 1053-1064. https://doi.org/10.5267/j.msl.2012.03.016

Mattila, A. S., \& Enz, C. A. (2002). The role of emotions in service encounters. Journal of Service Research, 4(4), 268-277. https://doi.org/10.1177/1094670502004004004

McGoldrick, P., Betts, E., \& Keeling, K. (1999). Antecedents of spontaneous buying behavior during temporary markdowns. Advances in Consumer Research, 26, 26-33.

Noble, S., Haytko, D., \& Phillips, J. (2009). What drives college-age Generation Y consumers?. Journal of Business Research, 62(6), 617628. https://doi.org/10.1016/j.jbusres.2008.01.020

Park, E., \& Kim, E. (2008). Effects of consumer tendencies and positive emotion on impulse buying behavior for apparel. Journal of The Korean Society of Clothing and Textiles, 32(6), 980-990. https://doi.org/10.5850/jksct.2008.32.6.980

Park, E., Kim, E., \& Forney, J. (2006). A structural model of fashionoriented impulse buying behavior. Journal of Fashion Marketing and Management: an International Journal, 10(4), 433-446.

https://doi.org/10.1108/13612020610701965
Ramanathan, S., \& Menon, G. (2006). Time-varying effects of chronic hedonic goals on impulsive behavior. Journal of Marketing Research, 43(4), 628-641. https://doi.org/10.1509/jmkr.43.4.628

Rook, D. (1987). The buying impulse. Journal of Consumer Research, 14, 189-199. https://doi.org/10.1086/209105

Rook, D., \& Fisher, R. (1995). Normative influences on impulsive buying behavior. Journal of Consumer Research, 22, 305-313. https://doi.org/10.1086/209452

Santini, F., Ladeira, W., Vieira, V., Araujo, C., \& Sampaio, C. (2018). Antecedents and consequences of impulse buying: a meta-analytic study. RAUSP Management Journal, 54(2), 178-204.. https://doi.org/10.1108/rausp-07-2018-0037

Santos, C. (2016). A influência da publicidade no consumo juvenil de marcas de vestuário e de calçado: um estudo de caso. International Journal of Marketing, Communication and New Media, 4(7), 85-105.

Sharma, P., Sivakumaran, B., \& Marshall, R. (2010). Impulse buying and variety seeking: A trait-correlates perspective. Journal of Business Research, 63(3), 276-283. https://doi.org/10.1016/j.jbusres.2009.03.013

Solomon, M. (2014). Consumer behavior: buying, having and being (11th ed.). Boston: Pearson Education, Inc.

Stern, H. (1962). The significance of impulse buying today. Journal of Marketing, 26, 59-62. https://doi.org/10.2307/1248439

Tajfel, H. (1972). Some developments in European social psychology. European Journal of Social Psychology, 2, 307-322.

Taute, H., \& McQuitty, S. (2004). Feeling Good! Doing Good! An exploratory look at the impulsive purchase of the social good. Journal of Marketing Theory and Practice, 12(2), 16-27. https://doi.org/10.2307/40470134

Teiga, A. (2019). "Vende-se paixão": Determinantes psicossociais da compra por impulso em adeptos de futebol. (Tese de Mestrado), Universidade do Porto, Portugal.

Tendai, M., \& Crispen, C. (2009). In-store shopping environment and impulsive buying. African Journal of Marketing Management, 1(4), 102-108.

Tonetto, L. M., Brust-Renck, P. G., \& Stein, L. M. (2014). Perspectivas metodológicas na pesquisa sobre o comportamento do consumidor. Psicologia: Ciência e Profissão, 34(1), 180-195. http://dx.doi.org/10.1590/S1414-98932014000100013

Virvilaite, R., Saladiene, V., \& Bagdonaite, R. (2009). Peculiarities of impulsive purchasing in the market of consumer goods. Inzinerine Ekonomika-Engineering Economics, Commerce of Engineering Decisions, 2, $101-108$

Vohs, K., \& Faber, R. (2007). Spent resources: self-regulatory resource availability affects impulse buying. Journal of Consumer Research, 33(4), 537-547. https://doi.org/10.1086/510228

Wänke, M. (2009). What's social about consumer behavior? In M. Wänke (Ed.), Social psychology of consumer behavior (pp. 3-18). New York: Psychology Press.

Wood, M. (1998). Socio-economic status, delay of gratification, and impulse buying. Journal of Economic Psychology, 19(3), 295-320. https://doi.org/10.1016/S0167-4870(98)00009-9

Youn, S. (2000). The dimensional structure of consumer buying impulsivity: measurement and validation. (Doctoral Thesis), University of Minnesota, Minneapolis.

Youn, S., \& Faber, R. (2002). The dimensional structure of consumer buying impulsivity: Measurement and validation. In S. Broniarczyk \& K. Nakamoto (Eds.), North American advances in consumer research 22 (Vol. 29, pp. 280). Valdosta: Association for Consumer Research. 